\title{
SYNTHESIS OF 3-HYDROXY-2-OXINDOLE DERIVATIVES WITH POTENTIAL ANTIGLAUCOMIC ACTIVITY
}

\section{A.M. Efremov', R.O. Eremeev', V.N. Ivanov', E.V. Sokolova², V.G. Klochkov²}

\author{
${ }^{1}$ Department of Chemistry, Lomonosov Moscow State University, \\ 119234, Russia, Moscow, Leniskie Gory St., 1. \\ ${ }^{2}$ Research Institute of Pharmacology, Volgograd State Medical University, \\ 400001, Russia, Volgograd, KIM St. 20
}

DOI: 10.19163/MedChemRussia2021-2021-356

E-mail: sash-ka.e@yandex.ru

Novel 3-hydroxy-2-oxindole derivatives were synthesized using the microwave-assisted (MW) decarboxylative condensation of substituted isatins with malonic and cyanoacetic acids. Starting compounds were synthesized previously in our laboratory [1]. New 5-arylisatin compounds were obtained using Suzuki reaction, catalyzed by $\mathrm{Pd}(\mathrm{dppf}) \mathrm{Cl}_{2}$ [2]. A number of 5-sulfonamide compounds was obtained. Various 3-hydroxy-2-oxindoles were synthesized using MW activation for 5-10 min with high yields (up to 98\%). One-pot approach to synthesis of amine-substituted 3-hydroxy-2-oxindoles was developed. The inhibitory activity of synthesized compounds against quinone reductase 2 (NQO2 is possible molecular target for intraocular pressure (IOP) reduction) was studied in vitro. The influence of novel compounds on IOP was studied in vivo on normotensive rabbits. The lead compound was found to reduce the IOP by 5,6 $\mathrm{mmHg}$ and inhibit NQO2 $\left(\mathrm{IC}_{50}=77,4 \pm 27,3 \mu \mathrm{M}\right)$.

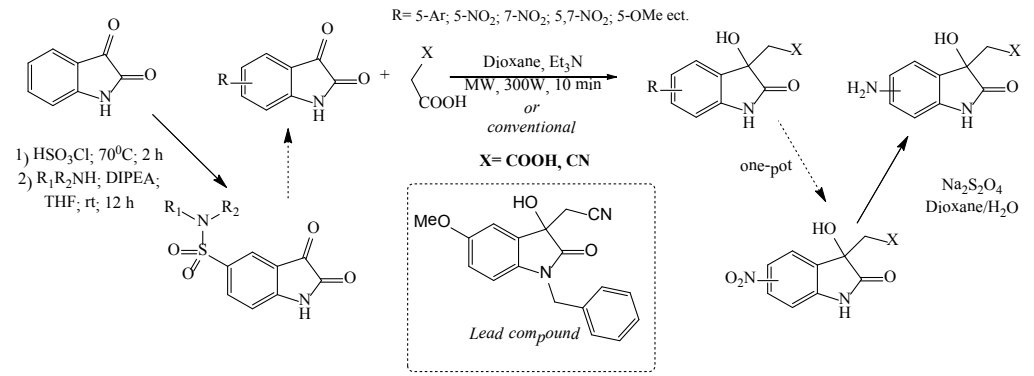

This work was supported by the Russian Foundation for Basic Research

(Project 20-03-00915\20) and by the Foundation for Assistance to Small

Innovative Enterprises, “UMNIK” program (15556ГY/2020 date 05.07.2020).

\section{References}

[1] Zaryanova E.V., Lozinskaya N.A., Beznos O.V., Volkova M.S., Chesnokova N.B., Zefirov N.S. Bioorganic and Medicinal Chemistry Letters, 2017, Vol. 27, P. 3787-3793

[2] Agamennone M., Belov D.S., Laghezza A., Ivanov V.N., Novoselov A.M., Andreev I.A., Ratmanova N.K., Altieri A., Tortorella P., Kurkin A.V. ChemMedChem 2016, Vol. 11, P. $1892-1898$ 